\title{
Evaluation of YouTube videos related to intubation in the pandemic process in terms of quality and content in Turkish and English
}

\author{
๑Münire Babayiğit ${ }^{1}$, $\odot$ Mustafa Alparslan Babayiğit ${ }^{2}$ \\ ${ }^{1}$ Keçiören Training and Research Hospital, Department of Anesthesiology and Reanimation, Ankara, Turkey \\ ${ }^{2}$ Public Health Consultant, Ankara, Turkey
}

Cite this article as: Babayiğit M, Babayiğit MA. Evaluation of YouTube videos related to intubation in the pandemic process in terms of quality and content in Turkish and English. Anatolian Curr Med J 2021; 3(3); 234-238.

\begin{abstract}
Aim: YouTube videos, which are used as sources of information, can also be an essential resource in intubation training. For this reason, we aimed to investigate the content, adequacy, and reliability of the training videos on intubation in our searches in Turkish and English.

Material and Method: This study was carried out between8 May to 9 May 2021by searching Youtube in Turkish and English with 'entübasyon' and 'intubation.' Forty four videos that met the inclusion criteria were included. Intubation indication, explanation of complications, number of views, number of likes, video power index (likes ratio*view rate/100) were recorded in the video content. Ten items were scored over ten total points after the subject content was evaluated.

Results: Although the number of views, the number of likes, and the power index values were higher in English videos, the difference was not statistically significant ( $\mathrm{p}>0.05)$. No significant difference was found between Turkish and English videos in the quality evaluation ( $\mathrm{p}>0.05$ ). Although it was seen that the approach to the patient diagnosed with Covid-19 (30.4\% vs. $9.5 \%)$ and the pediatric approach ( $8.7 \%$ vs. $0.0 \%)$ were mentioned at higher rates in the English videos, no significant difference was detected $(\mathrm{p}>0.05)$.

Conclusions: Video sharing on endotracheal intubation in Turkish and English has similar features. Educational videos are shared in Turkish, especially by academic institutions.
\end{abstract}

Keywords: Intubation, internet, video, YouTube

\section{INTRODUCTION}

Avicenna (980-1037) described the first endotracheal intubation practice. Curry performed the first human cadaver intubation in 1792. Magill first applied intubation in 1920 to give anesthesia. It was used for the first time in Turkey by Dr Burhaneddin Toker and Dr. Sadi Sun in 1949 (1). The intubation process provides keeping the airway open, controlling the airway and breathing, relieving the respiratory burden, and preventing aspiration.

It is crucial to make the necessary preparations for intubation, position the head and neck appropriately, and place the laryngoscope correctly. In addition, it is an intubation procedure that is desired to select the proper size tube, provide sedation and remove secretions, and then advance the tube between the vocal cords as soon as possible with non-traumatic movement $(2,3)$. When done correctly and quickly, without causing morbidity, intubation is life-saving by providing a reliable airway. It is an essential part of in-service training for every healthcare worker to acquire intubation skills (1-4).

Millions of videos are shared on YouTube, the videosharing site established in February 2005, and the number of shared videos is increasing day by day. There are also many videos on health-related topics on the site where almost every subject is shared (5). It is thought that online information sharing and search for education and health issues have increased, especially during the pandemic. However, the fact that video sharing is free and professional competence is not sought raises doubts about the reliability of the information (6-9). 
In the Covid-19 pandemic caused by the SARS-COV-2 virus, significant changes and restructurings have occurred in the health system. In this process, in-service training was organized, and the training of intubation, which is one of the primary duties of health workers, was repeated. However, there may be difficulties in conducting this training face-to-face. During the pandemic process, it is seen that educational videos for health professionals have been published along with the videos published on subjects such as the transmission routes of the disease and prevention. When the literature is examined, no study has been found that evaluates intubation videos on YouTube as a source of information. For this reason, we aimed to investigate the content, adequacy, and reliability of the training videos on intubation in our searches in Turkish and English.

\section{MATERIAL AND METHOD}

This observational study was carried out on Youtube between 8 May to 9 May 2021 by searching in Turkish and English with entübasyon and intubation. In the study, 44 of the elective endotracheal and rapid serial endotracheal intubation videos, in Turkish and English, with a duration of 2-20 minutes, were included. Videos in other languages containing other topics, repetitive, containing advertisements, non-educational, non-audio narration, and advanced airway applications such as nasotracheal intubation, fiberoptic intubation, retrograde intubation were excluded study. Two researchers analyzed the videos. Due to nature of this study, ethics committee approval was not obtained.

Intubation indication, explanation of complications, number of views, number of likes, video power index

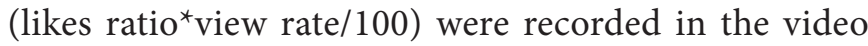
content. It was recorded whether the intubation application was shown on the patient, on a model, or as an animation. Subject content-preparation, tools, 2-Preoxygenation, 3-Anesthesia, paralysis, 4-Ventilation, 5-Difficult ventilation, 6-Intubation phase, 7-Difficult intubation, 8-Confirmation, 9-Postintubation management, 10-Management in the case of failed intubation, the explanation of management issues were evaluated. The content was scored over ten total points.

Intubation expression was recorded in pediatric and adult patients. In the video content, the features of intubation in patients with a diagnosis of Covid-19 or suspected were examined. In addition, the video tutorial was evaluated by a public health specialist and an experienced anesthesiologist as 1: little, 2: moderate, 3 : very useful for healthcare professionals who have no experience with intubation, and it was recorded.

\section{Statistical Analysis}

Continuous variables, median (minimum-maximum), categorical data were expressed as numbers and percentages. In the intergroup analysis of continuous variables, normality analyzes were performed with the Kolmogorov-Smirnov Goodness of Fit Test. Mann Whitney U Test was used for comparisons between groups as the data were not suitable for normal distribution. Chisquare test (Fisher's exact test when necessary) was used to compare categorical data. Analyzes were performed with IBM SPSS Package Program version 22.0 (IBM Corporation, Armonk, NY, USA). Cases where the type 1 error level was below 5\% were considered statistically significant.

\section{RESULTS}

The median video length of Turkish videos is 7.2 (2.119) minutes, the content is $6(1-11)$, the number of views is $11.662(14-4.160 .600)$, the number of likes is 143 (7$36.000)$, the number of dislikes is $6(0-1200)$ and power index median value is $10.917(10-1.497 .816 .000)$, while median video length of English videos is 6.5 (2-19) minutes, content is $6(2-9)$, number of views is 28.336 (764 -972.269), the number of likes was $173(0-11.000)$, the number of dislikes was 7 (0-292), and the median value of the power index was 19.818 (0 - 96.605.410). Although the number of views, the number of likes and the power index values were higher in English videos, the differences were not statistically significant $(\mathrm{p}>0.05)$ (Table 1).

\begin{tabular}{|c|c|c|c|}
\hline & $\begin{array}{c}\text { Turkish videos } \\
\text { [Median (min- } \\
\text { max)] } \\
(\mathbf{n}=21)\end{array}$ & $\begin{array}{c}\text { English videos } \\
\text { [Median (min- } \\
\text { max)] } \\
(\mathbf{n}=23)\end{array}$ & $\mathbf{p}$ \\
\hline Video length & $7.2(2.1-19)$ & $6.5(2-19)$ & $0.689^{*}$ \\
\hline Content & $6(1-10)$ & $6(2-9)$ & $0.487^{\star}$ \\
\hline $\begin{array}{l}\text { Number of } \\
\text { views }\end{array}$ & $\begin{array}{c}11.662 \\
(14-4.160 .600)\end{array}$ & $\begin{array}{c}28.336 \\
(764-972.269)\end{array}$ & $0.142^{*}$ \\
\hline $\begin{array}{l}\text { Number of } \\
\text { likes }\end{array}$ & $143(7-36.000)$ & $173(0-11.000)$ & $0.613^{*}$ \\
\hline $\begin{array}{l}\text { Number of } \\
\text { dislikes }\end{array}$ & $6(0-1200)$ & $7(0-292)$ & $0.612^{*}$ \\
\hline Powerindex & $\begin{array}{c}10.917 \\
(10-1.497 .816 .000)\end{array}$ & $\begin{array}{c}19.818 \\
(0-96.605 .410)\end{array}$ & $0.549^{*}$ \\
\hline \multicolumn{4}{|c|}{ * Mann Whitney U Test } \\
\hline
\end{tabular}

While the rate of finding indications in English videos $(43.5 \%)$ was higher than in Turkish videos $(28.6 \%)$, the difference was not significant $(\mathrm{p}>0.05)$. The complication rate was found to be statistically significantly higher in Turkish videos (28.6\%) than in English (4.3\%) videos $(\mathrm{p}=0.042)$. It has been observed that no wrong, 
incorrect or misleading information was given in any of the videos. While the application rates were higher in Turkish videos (76.2\% vs. $47.8 \%)$, the application rates were higher in English videos on the patient (21.7\% vs. $4.8 \%)$, but there was no significant difference ( $\mathrm{p}>0.05)$. ). No significant difference was found between Turkish and English videos in the quality evaluation ( $p>0.05)$. Although it was seen that the approach to the patient diagnosed with Covid-19 (30.4\% vs. 9.5\%) and the pediatric approach $(8.7 \%$ vs. $0.0 \%)$ was mentioned at higher rates in the English videos, no significant difference was detected ( $\mathrm{p}>0.05$ ) (Table 2).

\begin{tabular}{|c|c|c|c|}
\hline & $\begin{array}{l}\text { Turkish } \\
\text { Videos } \\
(\mathbf{n}=21)\end{array}$ & $\begin{array}{l}\text { English } \\
\text { Videos } \\
(\mathbf{n}=23)\end{array}$ & $\mathbf{p}$ \\
\hline $\begin{array}{l}\text { Indication expression }(\mathrm{n}, \%) \\
\text { No } \\
\text { Yes }\end{array}$ & $\begin{array}{c}15(71.4 \%) \\
6(28.6 \%)\end{array}$ & $\begin{array}{l}13(56.5 \%) \\
10(43.5 \%)\end{array}$ & $0.360^{\star a}$ \\
\hline $\begin{array}{l}\text { Complication expression }(\mathrm{n}, \%) \\
\text { No } \\
\text { Yes }\end{array}$ & $\begin{array}{c}15(71.4 \%) \\
6(28.6 \%)\end{array}$ & $\begin{array}{c}22(95.7 \%) \\
1(4.3 \%)\end{array}$ & $0.042^{\star a}$ \\
\hline $\begin{array}{l}\text { Video uploader (n,\%) } \\
\text { Academic Institution } \\
\text { Individual } \\
\text { Unknown }\end{array}$ & $\begin{array}{l}13(61.9 \%) \\
8(38.1 \%) \\
0(0.0 \%)\end{array}$ & $\begin{array}{l}16(69.6 \%) \\
5(21.7 \%) \\
2(8.7 \%)\end{array}$ & $0.232^{\star}$ \\
\hline $\begin{array}{l}\text { Contents of application }(\mathrm{n}, \%) \\
\text { No } \\
\text { Patient } \\
\text { Mannequin } \\
\text { Animation }\end{array}$ & $\begin{array}{c}1(4.8 \%) \\
1(4.8 \%) \\
16(76.2 \%) \\
3(14.3 \%)\end{array}$ & $\begin{array}{c}4(17.4 \%) \\
5(21.7 \%) \\
11(47.8 \%) \\
3(13.0 \%)\end{array}$ & $0.150^{*}$ \\
\hline $\begin{array}{l}\text { Instructiveness }(\mathrm{n}, \%) \\
\text { Little } \\
\text { Middle } \\
\text { Very }\end{array}$ & $\begin{array}{l}4(19.0 \%) \\
11(52.4 \%) \\
6(28.6 \%)\end{array}$ & $\begin{array}{l}5(21.7 \%) \\
11(47.8 \%) \\
7(30.4 \%)\end{array}$ & $0.953^{\star}$ \\
\hline $\begin{array}{l}\text { Application in Covid-19 (n,\%) } \\
\text { No } \\
\text { Yes }\end{array}$ & $\begin{array}{c}19(90.5 \%) \\
2(9.5 \%)\end{array}$ & $\begin{array}{c}16(69.6 \%) \\
7(30.4 \%)\end{array}$ & $0.137^{\star a}$ \\
\hline $\begin{array}{l}\text { Patient population }(\mathrm{n}, \%) \\
\text { Pediatric patient } \\
\text { Adult patient } \\
\text { Pediatric and adult patient }\end{array}$ & $\begin{array}{c}0(0.0 \%) \\
20(95.2 \%) \\
1(4.8 \%)\end{array}$ & $\begin{array}{c}2(8.7 \%) \\
20(87.0 \%) \\
1(4.3 \%)\end{array}$ & $0.384^{*}$ \\
\hline
\end{tabular}

\section{DISCUSSION}

Every healthcare worker should know about intubation and cardiopulmonary resuscitation. Even though inservice training was organized on these subjects at regular intervals, face-to-face training was interrupted during the pandemic process, and online training was primarily organized via the internet. Therefore, YouTube videos are of great importance as an educational tool in that they can be accessed anywhere, anytime, even via phones. In particular, the need for training on intubation has increased. Giving intubation training primarily on models is preferred as a safe method (10). Our study observed that the applications mainly were made on models in video types in both languages. There was no statistically significant difference between the two groups regarding application demonstrations on the model or the patient. Unlike our study, it was stated in other studies on intubation that the practices were more frequently demonstrated on patients. Because our study was carried out during the pandemic process, it is thought that the applied videos on the model may have been shared more.

A study shows that internet users perceive themselves as more competent and in control due to accessing information found on a website (11). The presence of visual expression in addition to theoretical knowledge increases interest and learning. Especially in medical interventions, visual representation is preferred by healthcare professionals. However, the reliability of the videos on the narration of medical practices is questioned, and academic studies are carried out on this subject. Pant et al., in their study, examined Youtube videos about acute myocardial infarction. They reported that the reliability of the posts on this life-threatening issue is low, that video recordings of traditional associations are not available on this site, and that some information given to patients is risky (5). Our study determined that most of the videos in both languages were prepared by academic institutions. It has been observed that no wrong, incorrect or misleading information was given in any of the videos. In these videos, in which a specific medical application is explained, it is seen that the narrators are health professionals and provide reliable information.

Endotracheal intubation is an important procedure that must be done meticulously and risky in transmission, since it is a procedure with high viral load, upper respiratory tract secretions and aerosol release. The healthcare worker performing the endotracheal intubation is close to the patient's airway before, during, and after the procedure (11).

Some protective measures and protocols are recommended for the intubation of patients diagnosed with COVID-19 (11-13). Using intubation boxes to prevent droplet spread, performing procedures in isolation rooms suitable for airborne infections, performing intubation practices with a separate special team, and only necessary personnel enter the operation room, cleaning and disinfection of the room after the procedure and the use of personal protective equipment (PPE) are some of these $(11,12)$. In particular, the use of WCE and the participation of a limited number of personnel in the procedure are important, and it was observed that these precautions were explained in all videos that talked about intubation in a patient with COVID-19. 
In a study evaluating the content and quality of information about intubation videos on YouTube, the posts were insufficient and unsafe in terms of content (15). Akça et al., in their study, examined the videos published in English in which rapid serial intubation was explained and found that the majority of the videos did not comply with the ACLS-RSI (Advanced Cardiac Life Support-Rapid Sequence Intubation) guideline (16). In our study, ten items were created by adding additional criteria to these criteria, and evaluation was made over ten points. The median values of the content of the videos in both languages were found to be similar, with 6/10. In general, every step of the intubation application was not explained, and in some videos, only endotracheal tube placement was explained. However, when the researchers on endotracheal intubation examined the videos, it was determined that half of the videos were helpful as a learning tool and one-third were very useful.Two studies evaluate YouTube videos as a general information source for tonsillectomy and ventilation tube placement specific to otolaryngology. Both studies found that the percentage of correct and valuable videos was less than $25 \%(17,18)$. Compared to these studies, in which videos of patients and their relatives are shared, it is seen that there is a more reliable and helpful information rate in our study since health professionals share the technique of applying a medical skill.

Airway management and intubation attempt are some of the essential medical skills for healthcare professionals. Intubation and mechanical ventilation may be required to ensure adequate oxygenation in respiratory failure. Respiratory failure due to diffuse lung involvement may also develop in the COVID-19 clinic. In many countries, the number of patients has exceeded the health system's capacity due to the pandemic. In these extraordinary conditions, while anesthesiologists and health personnel with intensive care experience were assigned to intensive care units, the number and capacity increasing day by day, all elective health practices were terminated, and other health workers were assigned to pandemic services. Therefore, intubation practices were sometimes performed by healthcare professionals other than anesthesiologists or intensive care physicians.

\section{CONCLUSION}

In our age, online content that can be found anytime and anywhere on laptops, tablets, and smartphones is replacing the use of traditional textbooks. It is seen that video sharing for medical applications such as endotracheal intubation is an important learning tool, and useful videos are shared in Turkish, especially by academic institutions.

\section{ETHICAL DECLARATIONS}

Ethics Committee Approval: Due to nature of this study, ethics committee approval was not obtained.

Conflict of Interest Statement: The authors have no conflicts of interest to declare.

Relationship between Financial Support and Interest: There is no person/organization that supports the study financially and the authors do not have any interestbased relationship

Author Contributions: All of the authors declare that they have all participated in the design, execution, and analysis of the paper, and that they have approved the final version.

\section{REFERENCES}

1. Luckhaupt $\mathrm{H}$, Brusis T. History of intubation. Laryngologie, Rhinologie, Otologie 1986; 65: 506-10.

2. Wang HE, Yealy DM. How many attempts are required to accomplish out-of-hospital endotracheal intubation? Acad Emerg Med 2006; 13: 372-7.

3. Asai T, Marfin AG. Ease of insertion of the laryngeal tube during manual-in-line neck stabilisation. Anaesthesia 2004; 59: 1163-6.

4. Lim M, Celaschi DA. Rapid sequence intubation: how do we define success? Can J Anaesth 2004; 51: 858.

5. Pant S, Deshmukh A, Murugiah K, et al. Clinical investigations assessing the credibility of the "YouTube approach "” to health information on acute myocardial infarction. Clinical Cardiology 2012; 285: 281-5

6. Yuksel B, Cakmak K. Healthcare information on YouTube : Pregnancy and COVID - 19. Int J Gynaecol Obstet 2020; 150: 189-93.

7. Li HO, Bailey A, Huynh D, Chan J. YouTube as a source of information on COVID-19: a pandemic of misinformation? BMJ Glob Health 2020; 5: e002604.

8. Ramirez MG, Rojas Travesedo RG, Martinez AA. YouTube and coronavirus : analysis of video consumption on the COVID-19 pandemic YouTube y coronavirus: análisis del consumo de vídeos sobre la. Rev Lat Comun Soc 2020; 78: 121-53.

9. Ataç Ö, Özalp YC, Kurnaz R, Güler OM, İnamlık M, Hayran O. Youtube as an Information Source During the Coronavirus Disease (COVID-19) Pandemic: Evaluation of the Turkish and English Content. Cureus 2020; 12: e10795.

10. Yüksel EM, İzdeş S. Safe intubation, sedation and neuromuscular block in COVID-19. In: Yamanel HL (Ed). Critical Care and COVID-19. 1st edition. Ankara: Türkiye Klinikleri 2020; 21-6.

11. Lemire M, Sicotte C, Paré G. Internet use and the logics of personal empowerment in health. Health Policy 2008; 88: 13040.

12. Duggan LV, Mastoras G, Bryson GL. Tracheal intubation in patients with COVID-19. CMAJ 2020; 192: E607.

13. Matava CT, Kovatsis PG, Summers JL, et al. Pediatric airway management in covid-19 patients - consensus guidelines from the society for pediatric anesthesia's pediatric difficult intubation collaborative and the Canadian Pediatric Anesthesia Society. Anesth Analg 2020; 13: 10.

14. Brewster DJ, Chrimes N, Do TB, et al. Consensus statement: Safe Airway Society principles of airway management and tracheal intubation specific to the COVID-19 adult patient group. Med J Aust 2020; 212: 472-81. 
15. Ocak U. Evaluation of the content, quality, reliability and accuracy of YouTube videos regarding endotracheal intubation techniques. Niger J Clin Pract 2018; 21: 1651-5.

16. Akça AH, Şaşmaz Mİ. YouTube for Rapid Sequence Intubation Learning, Is It Reliable? Van Tip Derg 2018; 25: 207-12.

17. Sorensen JA, Pusz MD, Brietzke SE. International Journal of Pediatric Otorhinolaryngology YouTube as an information source for pediatric adenotonsillectomy and ear tube surgery. Int J Pediatr Otorhinolaryngol 2014; 78: 65-70.

18. Strychowsky JE, Nayan S, Farrokhyar F, Maclean J. International Journal of Pediatric Otorhinolaryngology YouTube: A good source of information on pediatric tonsillectomy? Int J Pediatr Otorhinolaryngol 2013; 77: 972-5. 